\title{
Research on the Translation Teaching Cognitive Value Strategy Based on Network Catchwords
}

\author{
LiuYu \\ Nanchang Institute of Science \&Technology,Nanchang 330108,China
}

Keywords: Network catchword, Translation teaching, Cognitive value, Teaching strategy, Full transliteration.

\begin{abstract}
From the perspective of translation teaching, this paper studies the value of network catchwords, and proposes the translation teaching strategy based on cognitive value. Analyzing the formation and understanding of network catchwords, the analysis shows that network catchword is a process of social cultural cognition and creation, which should be taken into account the cognition and creation of cognitive subject in the process of translation. Based on the analysis of the cognitive value relevance of network catchword and translation teaching strategy, this paper puts forward the teaching strategies of incomplete translation and complete transliteration in view of the types of network catchwords, and puts forward a variety of the teaching strategy of comprehensive consideration translation when a word can be translated a variety of word. In order to network catchwords translated by the elegant word, this paper proposes the teaching strategy of the explanation translation, which provides a valuable reference for the study of translation teaching.
\end{abstract}

\section{Introduction}

In recent years, increasing the number of network catchword is very alarming, its content and form are also rich and colorful, and the increase of network catchword has caused the media, academia, public and government's extensive attention [1-3]. Network buzzwords in folk are constantly updated. "Quibble" editorial department since 2008 years had released new buzzwords for many consecutive years, and network buzzwords are reported by the authority of the official Xinhua news agency, it has become an important object of translation strategies and cognitive value research.

With the rapid development of network catchword, many researchers are interested in the research of network catchword, but the research is mostly limited to the language level, people needs to conduct a comprehensive in-depth analysis if we want to fully understand the network catchword and to explore its linguistic and social value [4,5]. Based on cognitive value as a starting point, the paper discusses the formation and understanding of network catchword to realize the objective and rational understanding of network catchword value, which provides the new perspective of translation and translation studies for the correct value of network catchword.

\section{Internal Cognitive Mechanism and Network Culture Language}

When people carry out their language activities, the similarity of their cognition is much higher than the outside world color and size. The cognitive behavior of the brain is a kind of subjective cognitive activity, and each category within the core has the same characteristics, between different characteristics can be homogeneous [6-8]. The network popular language is created in the process of cognition, and the similarity of language depends on people's cognitive activities, so teachers should take into account the cognitive value in the process of translation teaching, and specify a reasonable teaching strategy. 


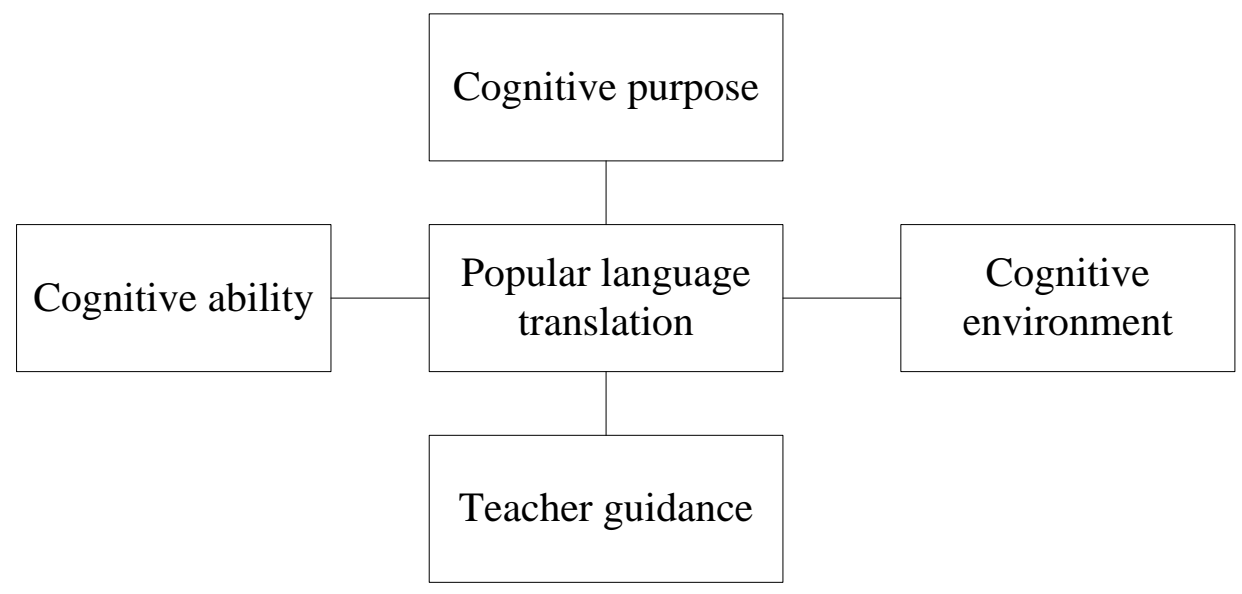

Fig.1 Translation teaching strategy and cognitive activity

Figure 1 shows the specified framework of translation teaching strategy based on network catchword. the cognitive process is related to cognitive purpose, cognitive ability and cognitive environment, therefore teachers need to consider these three factors in the specified translation teaching strategy, making different teaching strategies for different students.

\section{The Integration of Network Catchword and Cognitive Mechanism}

Network catchword is generally divided into two categories, in which one category is the symbol of the popular language, such as the 9494 is the same pronunciation with "jiushijiushi"; LG says the husband, which is the first letter of the alphabet [9]. The second category is the new vocabulary that is generally meaning to mix, such as "shengnv" word, sheng is left, nv is women, and the two words mix says the older unmarried young women.

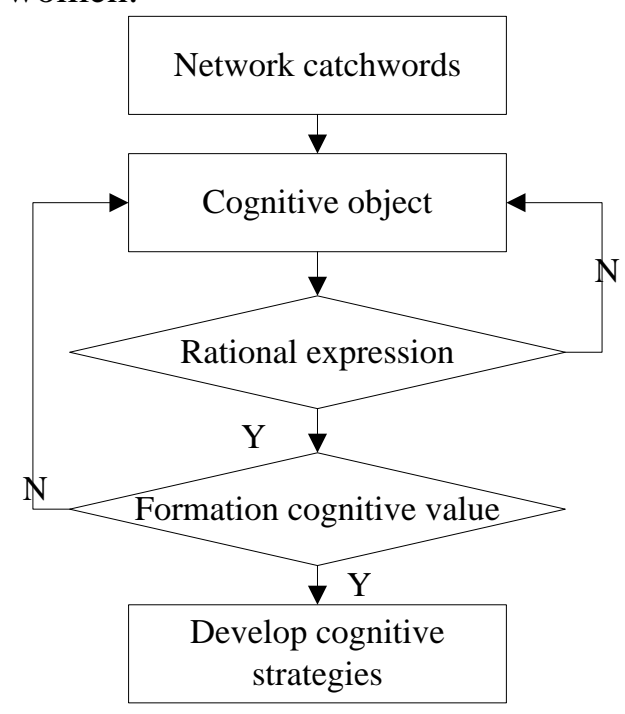

Fig. 2 The integration process of network catchword and cognitive mechanisms

Figure 2 shows the integration process of the network buzzwords and cognitive mechanism. Network popular language represents as specific expression in translation language; the cognitive value represents as the concept network, which represents as cognitive domain in the objective world. In the analysis of network popular language, we need to introduce two concepts, in which one is cognitive object, and another is cognitive medium. In the cognitive object, the use of the conventional method will not change to express, and the use of network language will change for the value of the cognitive changes. When the popular language is reasonable to the cognitive object, it will enter into the choice process of cognitive value; if it is not reasonable, it will be removed and can be processed on the cognitive object [10-11]. Through the cognitive value, we develop a reasonable cognitive teaching strategy, which can effectively improve the cognitive level of translation teaching and the accuracy of translation. 


\section{The Relevance of Network Catchword Cognitive Value in the Translation Teaching}

In the correlation analysis of network catchword and translation teaching cognitive value, there is an association between multiple cognitive objects. Assuming the correlation function of cognitive value is $y=f\left(x_{i}\right)$, the correlation degree is analyzed by using the three spline interpolation, the spline function $S_{3}(x)$ in each cell $\left[x_{i}, x_{i+1}\right]$ is expressed as:

$$
S\left(x_{i+\frac{1}{2}}\right)=\frac{1}{2}\left[f\left(x_{i}\right)+f\left(x_{i+1}\right)\right]
$$

In order to the relevance of the comprehensive translation teaching cognitive value and network catchword, the cognitive value and translation strategies are sorted, and the boundary equation of the integrated translation teaching strategy is established, the expression is:

$$
\left\{\begin{array}{l}
S_{3}\left(x_{i}-0\right)=S_{3}\left(x_{i}+0\right) \\
S_{3}^{\prime}\left(x_{i}-0\right)=S_{3}^{\prime}\left(x_{i}+0\right) \\
S_{3}^{\prime \prime}\left(x_{i}-0\right)=S_{3}^{\prime \prime}\left(x_{i}+0\right), \quad i=1,2, \ldots n-1
\end{array}\right.
$$

Among them, $x$ represents the value quantity. According to the three spline interpolation model, the end of the three related spline function meets the following formula.

$$
\begin{aligned}
& S_{3}\left(x_{0}+0\right)=S_{3}\left(x_{n}-0\right), S_{3}^{\prime}\left(x_{0}+0\right)=S_{3}^{\prime}\left(x_{n}-0\right) \\
& S_{3}^{\prime \prime}\left(x_{0}+0\right)=S_{3}^{\prime \prime}\left(x_{n}-0\right)
\end{aligned}
$$

The left and right ends between each cell $\left[x_{i}, x_{i+1}\right]$ are respectively

$$
S_{3}^{\prime \prime}\left(x_{i}\right)=\frac{6\left(y_{i+1}-y_{i}\right)}{h_{i}^{2}}-\frac{4 m_{i}+2 m_{i+1}}{h_{i}} .
$$

Among them, $m$ and $h$ represent the reference coefficient of cognitive value, after finishing it is simplified for

$$
\left(1-\lambda_{i}\right) m_{i-1}+2 m_{i}+\lambda_{i} m_{i+1}=\beta_{i} .
$$

According to the least square method, linear fitting can obtain the correlation equation.

$$
Q(a, b)=\sum_{i=1}^{N}\left[y_{i}-\left(a+b x_{i}\right)\right]^{2} .
$$

Among them, $a$ and $b$ respectively represent the proportion of cognitive value and cognitive strategy. In the process of translation teaching, we can adjust the proportion of parameters, achieving the matching between translation ability and cognitive process and improving students' translation ability, to specify a reasonable translation teaching strategy.

\section{The Value Choice of Network Popular Language Translation Teaching Method}

Popular language type and translation teaching value. From the perspective of universal translation, translation is a process of reverse thinking, such as "hold", "out", those words generally do not need to be translated, assuming that auxiliary can constitute a daily language. When people translates the "she is hard to get along /to control", we can translate into difficult "hold" live her; When people translates the "she is hard to get along /to control", we will be difficult to want to hold live; some can direct transliteration, such as " iPad " [12]. In the translation teaching course, the teacher should target at the characteristics and types of the popular language and specify the relevant popular language teaching strategies.

The value choice of translation subject. The network popular language itself is the cognitive subject value choice and judgment result, people need to consider the specific objects of these topics when translating. Such as "3S lady" a word, its translation has been discussed for many times, so far, the translation of the word has a lot of types, such as spinster or old maid is to the class as a traditional 
conservative "old girl", some translation is leftover, highlighting the type of person who leftovers like the loss of taste, there are also translated into women a onthe shelf; the translation is mainly highlight the unwanted features, the most direct translation is left women and single women, which said left and single women. Therefore, we can consider a variety of translation in the teaching of those words and the full range of translation for the translation subject.

The value choice of elegance and vulgar. The network language has the character of elegance and popularity, the elegant language often can not find the corresponding words in the translation, because the network language is conformity and metaphor, it is difficult to show the original style through the literal translation. Such as "cock wire" word, baidu dictionary will be the translation for the loser and pleb, which is elegantly translated, but the interpretation of the word is often"bitter young", he is a kind of person's self proclaimed from humble beginnings and homely young men, they are often claimed to" poor ugly dwarf fell fat and stupid because". In the process of translation, there are direct translation for semi tone diaos, the word is easy to understand; for a foreigner, they will be a head of fog when looking the word, some people simply translated into Penisfans, but such translation need to add annotations, otherwise it will be fully understood as indecent words. In fact, in order to let foreigners see the popular language of our country in the translation of these words,we can be added to explain the translation, improving the accuracy of translation. When teachers carry out translation teaching, people can be summarized in this kind of words, and addexplanatory translation in translation teaching, to improve the students' ability of translation these words.

\section{Summary}

This paper deeply researches on the formation and understanding mechanism of the network popular language, the research found that network catchwords is the subjective cognition of the cognitive subject and the process of creation, so we should be consider comprehensively the cognitive value of cognitive subject and social culture in the process of translation. Through the analysis of the relevance of translation teaching strategies and network popular language cognitive value, this paper summaries the value choice of network catchword translation teaching strategy, it includes the network catchword type and translation teaching value, the value choice of translation subject, the value choice of elegance and popularity, which provides a theoretical reference for the study of translation teaching.

\section{References}

[1] L.C. Ding. A description of the network metaphor and metonymy phenomenon in the perspective of cognitive linguistics. Anhui literature, 2013(5): 11-18.

[2] R. Ke. To see the network popular language from the perspective of social science. Media observation, 2013(2): 35-41.

[3] D.Q. Liu. Analysis of the network popular language. Language learning, 2013(3): 58-62.

[4] Y.Y. Yu. The translation strategies of Chinese popular language. Chinese translation of science and technology, 2013(4): 89-93.

[5] Y. Yang. The advantages and disadvantages of multimedia teaching in English teaching and learning. Journal of Jilin radio and television university, 2013(6): 146-147.

[6] Y.H. Zhang. A study on the dynamic evaluation model of web writing teaching in college English. Foreign language circles, 2014(4): 73-81.

[7] X.Q. Wang. Higher mathematics stratified teaching mode theory and its practice. Jilin education, 2014(11): 20- 21.

[8] D.H. Mao. Research on the implementation of higher vocational mathematic hierarchical teaching. Journal of Chongqing vocational and technical college, 2014,16(4): 43- 44. 
[9] B.P. Chen, A.L. Hu. Analysis of the stratified teaching mode in higher education popularization stage. Journal of Liaoning radio and TV university, 2014(2): 51- 52.

[10] X.Y. Liu. The research and practice of higher mathematics hierarchical teaching assessment method in higher vocational. China school education, 2014(3): 101 - 111.

[11] X.F. Han. Analysis of higher mathematics teaching current situation and thinking about the stratification teaching. Journal of Lvliang College, 2013, 23(1): 40- 41.

[12] L. Fu. The application of hierarchical teaching in English teaching. Hope monthly, 2013(8):100-101. 